\title{
Banach 空间中线性系统的稳定性
}

\author{
罗跃虎 (피) 翁绍鹏 (4) 冯德兴 \\ ( 中国科学院系统科学研究所, 北京 100080; 4香港大学数学系; (四)山西大学数学系, 太原 030006; \\ 南开大学数学系, 天津 300071)
}

无穷维空间中线性系统的稳定性是许多作者关注的问题. Gibson 在文献 [1] 中证明了如 下结果:

设 $T(t)$ 是 Hilbert 空间 $X$ 由 $A$ 生成的渐近稳定的 $C_{0}$ 压缩半群, 而 $B$ 为 $X$ 上紧线性算 子. 如果 $A+B$ 生成的 $C_{0}$ 半群 $S(t)$ 是指数稳定的, 则 $T(t)$ 必定也是指数稳定的. 因此, Hilbet 空间中一个非指数稳定的 $C_{0}$ 半群不可能通过紧反馈达到指数稳定.

Triggiani 在文献 [2] 中把 Gibson 的结果推广到具有“逼近性质” 的 Banach 空间 $X$. 本文用 非常简单的方法证明了 Gibson 的结果在任何 Banach 空间中都成立, 并且给出了 $C_{0}$ 半群的渐 近稳定性和指数稳定性等价的条件.

关于 Gibson 结果的推广, 我们有

定理 1 假设 $A$ 是 Banach 空间 $X$ 中渐近稳定的 $C_{0}$ 半群 $T(t)$ 的生成算子, 并且 $B$ 是 $X$ 中的紧线性算子. 如果 $A+B$ 生成的 $C_{0}$ 半群 $S(t)$ 是指数稳定的, 则 $T(t)$ 也是指数稳定的.

证 若不然, 即 $T(t)$ 不是指数稳定的, 则没有正常数 $t_{0}$ 使得 $\left\|T\left(t_{0}\right)\right\|<1$. 于是存在 一列正数 $\left\{\left.t_{n}\right|_{n} \geqslant 1\right\}$ 和 $X$ 中的一列元 $\left\{\left.x_{n}\right|_{n} \geqslant 1\right\}$ 使得

$$
\left\|x_{n}\right\|=1, \quad\left\|T(t) x_{n}\right\|>1-1 / n, \quad \forall n \geqslant 1 ; t_{n} \rightarrow \infty \text { (当 } n \rightarrow \infty \text { ). }
$$

由于 $S(t)$ 是指数稳定的, 并且 $B$ 是紧算子, 故集合

$$
Q \triangleq\left\{\left.B S(t) x\right|_{x} \in X, \quad\|x\|=1, t \geqslant 0\right\}
$$

是相对紧的. 从 $T(t)$ 的渐近稳定性可知, 存在一正常数 $M_{1}$ 使得 $\|T(t)\| \leqslant M_{1}, \forall t \geqslant 0$, 并且

$$
\lim _{t} \sup _{x \in Q}\|T(t) x\|=0 .
$$

由于 $S(t)$ 是指数稳定的, 故存在两个正常数 $M$ 和 $\omega$, 使得 $\|S(t)\| \leqslant M \mathrm{e}^{-}{ }^{-}, \forall t \geqslant 0$. 根据 线性算子半群扰动理论 ${ }^{[3]}$, 我们有

$$
S(t) x=T(t) x+\int_{0}^{t} T(t-s) B S(s) x \mathrm{~d} s, \quad \forall x \in X, \quad \forall t \geqslant 0 .
$$

于是对于任意 $T>0$, 当 $t_{n}>T$ 时, 得到

$$
\begin{aligned}
\left\|S\left(t_{n}\right) x_{n}\right\| & \geqslant 1-\frac{1}{n}-\left\|\int_{0}^{T} T\left(t_{n}-s\right) B S(s) x_{n} \mathrm{~d} s\right\|-\| \int_{T}^{t_{n}} T\left(t_{n}-s\right) B S(s) x_{n} \mathrm{~d} s \\
& \geqslant 1-\frac{1}{n}-T \sup _{0}\left\|T\left(t_{n}-s\right) B S(s) x_{n}\right\|-M M_{1}\|B\| \omega^{-1} \mathrm{e}^{-\varphi} .
\end{aligned}
$$

由式(1) 可知, $\lim _{n} \sup _{s}\left\|T\left(t_{n}-s\right) B S(s) x_{n}\right\|=0$. 于是, 在式(2) 中先让 $n \rightarrow \infty$, 再让 $T \rightarrow \infty$ 就得到 $\varlimsup_{n}\left\|S\left(t_{n}\right) x_{n}\right\| \geqslant 1$, 此与 $S(t)$ 的指数稳定性矛盾. 证毕.

由此定理可得下面的推论.

推论 1 设 $B$ 是 $X$ 中的紧线性算子, 并且 $T(t)$ 和 $S(t)$ 是分别由 $A+B$ 和 $A$ 所生成的 
$C_{0}$ 半群. 假设下列条件之一满足:

( ) $T^{*}(t)$ 是渐近稳定的, 并且 $T(t)$ 是 sun_自反的;

( ) 如果 $X$ 是自反的, $T^{*}(t)$ 是渐近稳定的, 则 $S(T)$ 是指数稳定的, 蕴含 $T(t)$ 也是指数稳定的.

关于渐近稳定和指数稳定的等价性, 我们给出

定理 2 设 $T(t)$ 是 Banach 空间 $X$ 中由线性算子 $A$ 生成的 $C_{0}$ 半群. 如果存在常数 $t_{0}>0$, 使得 $T(t)$ 在 $t=t_{0}$ 按算子范数连续, 并且 $A$ 具有紧豫解式, 则 $T(t)$ 的渐近稳定性与 其指数稳定性等价.

推论 2 设 $T(t)$ 是 Banach 空间 $X$ 中由线性算子 $A$ 生成的 $C_{0}$ 半群. 如果 $A$ 有紧豫解 式, 并且存在 $t_{0}>0$, 使得 $T(t)$ 在 $t=t_{0}$ 可微, 那么 $T(t)$ 的渐近稳定性与其指数稳定性等价.

注（）定理 2 和推论 2 中的渐近稳定性可以用弱渐近稳定性代替. ( ) 定理 2 中所 作的假设: 存在 $t_{0}>0$ 使得 $T(t)$ 在 $t_{0}$ 按算子拓扑连续, 不能去掉. 有例子说明定理 2 中所作 的假设: $A$ 有紧豫解式, 也是不能去掉的.

致谢 本工作为国家自然科学基金资助项目.

\title{
参 考 文 献
}

1 Gibson J S. A note on satbilization of infinite dimensional linear oscillators by compact feedback. SIAM Journal of Control \& Control, 1980, 18: 311 316

2 Triggiani R. Lack of uniform stabilization for noncontractive semigroups under compact perturbation. Proc Amer Math Soc, $1989,105(2): 375 \sim 383$

3 Curtain R F, Pritchard A J. Infinite Dimensional Linear System Theory. New York: Springer_Verlag, 1978

\section{消除 $\mathbf{B a F}_{2}$ 闪㷧探头快信号幅度随时间衰减的方法}

\author{
杨巨华 郭应焕 \\ (中国科学院高能物理研究所, 中国科学院核分析技术研究开放实验室, 北京 100080)
}

$\mathrm{BaF}_{2}$ 闪炼体具有良好的定时性能和高的探测效率, 现已广泛地应用于正电子湮没寿命谱 仪中 ${ }^{11]}$. 但这种探头存在快信号 (波长 $220 \mathrm{~nm}$, 光子能量 $5.52 \mathrm{eV}$, 苂光寿命 $100 \mathrm{~ns}$ ) 输出幅度 随时间缓慢衰减的缺点. 一般在 2 3 a 内幅度会减小 $1 / 4$. 这种情况在各实验室的正电子寿 命谱仪中都发生. 我们实验室曾遇到过一次在半年内幅度减小 $1 / 2$ 的严重情况. 这个问题通 常的解决办法是, 把探头在重新封装一次. 快信号衰减原因至今未探讨过. $\mathrm{BaF}_{2}$ 闪炼探头结 构如图 1 所示. 重新封装是旋下保护罩盖, 擦去硅油层, 再涂上新的硅油后封好.

经过对多次重新封装探头情况的分析发现, 这种信号幅度的衰减可能与 $\mathrm{BaF}_{2}$ 晶体和光电 倍增管石英窗之间硅油层的挤压程度有关. 衰减最快的一次是由于封装快, 操作时间短, 使封 装后的新硅油层较厚所致. 因此, 在探头重新封好后, 把探头坚立放置两周, 使晶体在自重力 下充分挤压硅油层, 最后把罩盖旋紧. 实验表明, 这比快速封装的硅油层减少约 $0.2 \mathrm{~mm}$. 这 样封装的探头, 其快信号的输出幅度半年内完全保持不变. $\mathrm{BaF}_{2}$ 闪伢探头的这种封装程序提 